\title{
Photosynthetic Responses to Sink-Source Manipulation in Five Peach Cultivars Varying in Maturity Date
}

\author{
Ben Hong Wu, Hai Qiang Huang, Pei Ge Fan, and Shao Hua Li ${ }^{1}$ \\ Institute of Botany, Chinese Academy of Sciences, Beijing 100093, China \\ Guo Jie Liu \\ College of Agronomy and Biotechnology, China Agricultural University, Beijing 100094, China
}

\begin{abstract}
AdDitional INDEX wORDs. Prunus persica, fruit removal, sink demand, substomatal $\mathrm{CO}_{2}$, stomatal and nonstomatal limitation
Abstract. Five peach cultivars [Prunus persica (L.) Batch] with different maturity dates were subjected to sinksource manipulation by girdling to isolate 1-year-old fruit-bearing shoots. Four treatments were performed: fruit were removed ( - fruit); one fruit ( +1 fruit) and two fruit ( +2 fruit) were kept inside two girdling cuts; and two fruit were kept outside two girdling cuts (-fruit*). Photosynthetic responses for the five cultivars were similar and did not show genotypic differences. Generally, net photosynthetic rate $(\mathrm{Pn})$, stomatal conductance $\left(g_{\mathrm{s}}\right)$, and transpiration rate (E) were higher, and leaf temperature (TI) was lower in +2 fruit than in +1 fruit, followed by - fruit and -fruit* which were not different. The results also indicated that water outflow from fruit into leaves did not influence photosynthesis, and lower photosynthesis in -fruit treatment was not due to water status of source leaves influenced by removing fruit. Pn tended to increase with Tl until Tl reached a critical level. Beyond the critical temperature level, Pn generally decreased. The critical TI was roughly identified as $34-37^{\circ} \mathrm{C}$ for the five cultivars. Both higher and lower substomatal $\mathrm{CO}_{2}(\mathrm{Ci})$ levels occurred in -fruit and -fruit* treatments than in +1 fruit and +2 fruit treatments, indicating that decreased Pn could be due to both nonstomatal and stomatal limitations. Further analysis of the relationship between $\mathrm{Ci}$ and photosynthetically active radiation $(P A R)$ showed that nonstomatal limitation under low sink demand took place mostly under high $P A R$. Thus, high light intensity, combined with TI may play an important role in leaf photosynthetic regulation.
\end{abstract}

Leaf photosynthesis in higher plants depends upon not only environmental conditions such as air temperature (Zhang et al., 2001) but also internal regulation and genetic factors. Internal regulation can be influenced by manipulations affecting the source organs, such as by shading leaves, and by treatments affecting the sink organs, such as by removing fruit (Syvertsen et al., 2003). Fruit is the most important assimilate sink in fruit trees. It was reported that the dry matter of fruit could exceed $50 \%$ of the total dry matter production of a tree at harvest (Pavel and DeJong, 1993). Therefore, removing all or some fruit has often been used to vary the sink-source relationship so as to investigate photosynthetic responses.

Decreasing sink demand by removing fruit generally reduced leaf photosynthetic rate in many species, such as tomato (Lycopersicum esculentum Mill.) (Walker and Ho, 1977), grape (Vitis vinifera L.) (Downton et al., 1987), kiwifruit (Actinidia deliciosa Liang et Ferguson) (Buwalda and Smith, 1990), and Satsuma mandarin (Citrus unshiu Marc.) (Iglesias et al., 2002). Similarly, in peach trees, the photosynthetic rate was greater for leaves with a high crop load than a low crop load (Quilot et al., 2004). Li et al. (2005) reported that fruit removal resulted in a $50 \%$ to $56 \%$ reduction in net photosynthetic rate in 'Okubo' peach and a $22 \%$ to $39 \%$ reduction in 'Yanfeng 1' peach, compared with fruit-bearing shoots. However, this effect

Received for publication 2 May 2007. Accepted for publication 24 Oct. 2007. Funding for this study was provided by the National Natural Science Foundation of China (30370986).

We thank Prof. Douglas D. Archbold, University of Kentucky, for critical review of the manuscript.

${ }^{1}$ Corresponding author. E-mail: shhli@ibcas.ac.cn. of reduced sink demand was not observed in photosynthetic capacity in studies of apple (Malus domestica Borkh.) (Rom and Ferree, 1986), sweet cherry (Prunus avium L.) (Roper et al., 1988), Satsuma mandarin (Okuda et al., 1996), and peach (DeJong, 1986). These inconsistent responses of leaf photosynthetic rate to sink-source modification may be due to differences in genotypic factors or developmental stage and the number of removed fruit.

Stomatal closure and $\mathrm{Tl}$ were reported to play important roles in photosynthetic reduction with weakened sink demand (Li et al., 2001, 2005). The depression in Pn was related to reduced stomatal aperture and increased $\mathrm{Tl}$, suggesting that stomatal aperture might be considered the trigger or promoter and leaf temperature as the actor for regulating photosynthesis when sink demand is low in peach ( $\mathrm{Li}$ et al., 2001, 2005). A small stomatal aperture resulted in low $\mathrm{E}$, and was followed by an increase in Tl. Reduced photochemical efficiency $\left(F_{\mathrm{v}} / F_{\mathrm{m}}\right)$ in leaves resulted from this higher $\mathrm{Tl}$ (Li et al., 2007).

Fruit may be a temporary water reservoir during the day time. Huguet et al. (1992) reported that shrinkage of apple fruit appeared during the light period due to water departure from fruit which acts as a reservoir. It seemed that, at high irradiation or temperature, water in fruit might replenish leaves to some degree, which may influence stomatal aperture. Therefore, in the previous studies, decreased photosynthesis by removing some or all fruit may have been associated with a leaf water deficit. In addition, $\mathrm{Tl}$ depended upon both the air temperature and the light energy received. It is, therefore, valuable to clarify the possible influence of the fruit water reservoir and environmental variables on photosynthetic responses under low sink demand. 
In the present study, five peach cultivars with maturity dates from the end of June to the end of September were selected to study photosynthetic responses to various levels of sink demand during the final rapid fruit growth stage. The main objective was to study genotypic differences in photosynthetic responses to sink-source manipulation. In addition, the possible influence of environmental variation, especially the light energy received by source leaves represented by $P A R$, and the fruit water reservoir on the photosynthetic responses were investigated.

\section{Materials and Methods}

Plant materials and treatments. The experiment was conducted in suburban Beijing (Pinggu District), China, in 2005. Five peach cultivars with different maturity dates [Qingfeng (late June), Okubo (early August), Yanhong (late August), Bayuecui (early September), and Wanmi (late September)] in the same orchard were used. Five-year-old trees were trained to the open system with spacing of $3 \times 5 \mathrm{~m}$. Routine fertilization, irrigation, and pest control suitable for commercial fruit production were provided.

One or two branches, located on the south side of the tree about $1-1.5 \mathrm{~m}$ above ground and homogeneous in vegetative and productive appearance, were selected on each of five trees for each cultivar. Four 1-year-old shoots, bearing two fruit of similar size, were used to manipulate sink-source relationships on each branch. One new shoot ( $>30 \mathrm{~cm}$ in length) with 10 fully expanded mature leaves (prepared by topping and removing the small basal leaves) was retained on each 1-year-old shoot. Two 10-mm-wide cuts were made, respectively, on the basal and apical parts of 1-year-old shoot with a girdling knife to isolate the experimental shoot and control the transport of assimilates between the treated and nonexperimental parts via the phloem, but allowing water flow via the xylem. Four treatments were applied to the four 1-year-old shoots on each branch, as shown in Fig. 1: fruit were removed (-fruit); one fruit (+1 fruit) or two

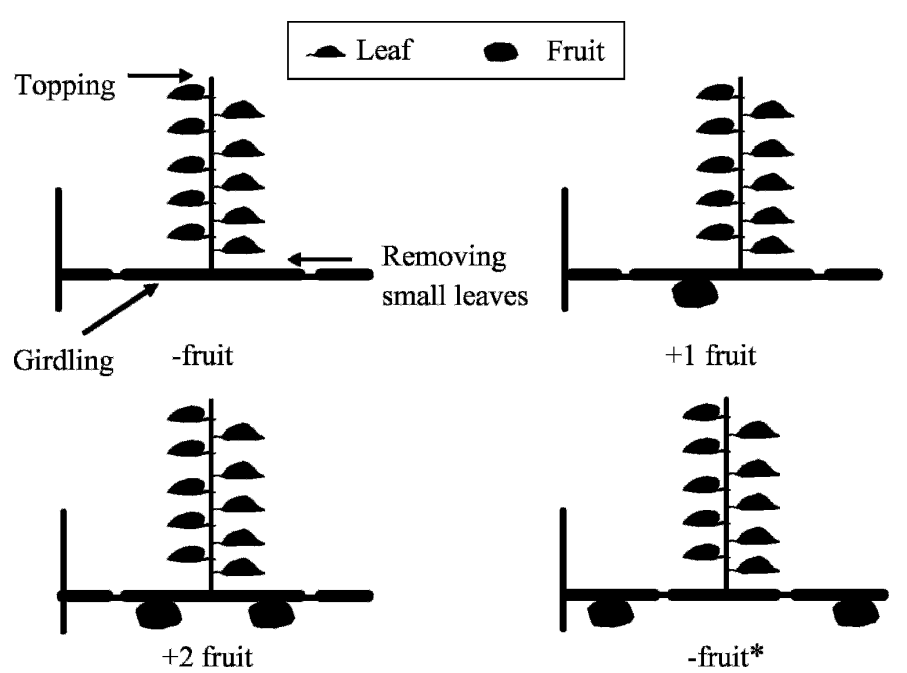

Fig. 1. Diagram of sink-source treatments on 1-year-old fruit-bearing shoots for peach. Ten fully expanded mature leaves were retained by topping and removing the small basal leaves. The basal and apical parts of fruit-bearing shoot were girdled with a 10 -mm-wide cut, isolating the shoots. Fruit were removed inside and outside the two girdling cuts: no fruit (-fruit), one fruit $(+1$ fruit), and two fruit ( +2 fruit) were kept inside the two girdling cuts; and two fruit were kept outside the two girdling cuts (-fruit*). fruit (+2 fruit) were kept within the girdling region; two fruit were kept outside two girdling cuts (-fruit*). Treatments were carried out during the final fruit rapid growth stage (15-20 d before maturity) for all the cultivars, on 16 June for Qingfeng, 26 July for Okubo, 17 Aug. for Yanhong, 21 Aug. for Bayuecui, and 18 Sept. for Wanmi.

Measurements. Gas-exchange measurements were taken on three random dates within $8 \mathrm{~d}$ after initiating the treatments. Net photosynthetic rates were measured every hour from 0800 to 1700 HR on one fully expanded leaf of each new shoot, using a portable gas-exchange analyzer (LI-6400; LI-COR, Lincoln, Neb.). Values for $g_{\mathrm{s}}, \mathrm{E}, \mathrm{Tl}, \mathrm{Ci}$, and $P A R$ were simultaneously obtained when Pn was measured.

Statistical analysis. Multiple comparisons were performed to detect differences in photosynthetic parameters among the treatments using mean data collecting from the three measurement dates for each of five cultivars. All data analyses and graphs were made with the S-Plus language (MathSoft, Cambridge, MA.).

\section{Results}

General photosynthetic Responses to Sink-SOURCE RELATIONSHIP. Mean Pn and other photosynthetic parameters across the three measurement dates during final fruit rapid growth stage for each cultivar are shown in Table 1. The influence of the sink-source manipulations on mean Pn was similar for the five peach cultivars. There was no significant difference in Pn between -fruit and -fruit* treatments. Fruit removal resulted in significantly lower Pn than +1 fruit and +2 fruit treatments. Pn, however, depended upon the number of fruit retained on the 1 -year-old shoot. The leaves of the +2 fruit treatment had significantly higher Pn than those of +1 fruit treatment in all cultivars except Qingfeng.

The responses of $g_{\mathrm{s}}$ and $\mathrm{E}$ to the sink-source manipulations were very similar to those of Pn for the five cultivars. Mean $g_{\mathrm{s}}$ and $\mathrm{E}$ significantly decreased in -fruit and -fruit* treatments, compared with those in +1 fruit and +2 fruit treatments. Higher $g_{\mathrm{s}}$ and $E$ were observed in +2 fruit than in +1 fruit treatment except for 'Qingfeng'. There were no significant differences in mean $g_{\mathrm{s}}$ and $E$ between the -fruit and -fruit* treatments. In contract to the effect on $\mathrm{Pn}, g_{\mathrm{s}}$, and $\mathrm{E}$, fruit removal resulted in increased $\mathrm{Tl}$ in -fruit and -fruit* treatments compared with +1 fruit and +2 fruit treatments. Tl did not significantly differ between the +2 fruit and +1 fruit or between -fruit and -fruit* treatments.

$\mathrm{Ci}$ did not exhibit a consistent response with varying sink demand for the five cultivars. No significant differences were found in mean $\mathrm{Ci}$ among the four treatments for 'Qingfeng' and 'Okubo'. However, a lower mean $\mathrm{Ci}$ was obtained in fruitremoval treatments (-fruit and-fruit*) than those in the +2 fruit and +1 fruit treatments for 'Bayuecui'. In contrast, fruit removal, the -fruit and-fruit* treatments, resulted in a higher $\mathrm{Ci}$ than the +2 fruit and +1 fruit treatments for 'Wanmi'. With 'Yanhong', a significantly higher $\mathrm{Ci}$ was found only between -fruit* and +1 fruit.

DIURNAL VARIATIONS IN NET PHOTOSYNTHETIC RATE AND OTHER PHOTOSYNTHETIC PARAMETERS. All five cultivars (Qingfeng, Okubo, Yanhong, Bayuecui, and Wanmi) exhibited similar diurnal variations; thus only the diurnal variations in photosynthetic parameters for Wanmi are presented (Fig. 2). The diurnal variations in Pn depended upon the occurrence and duration of high $P A R$. In the +2 fruit and +1 fruit treatments, 
Table 1. Net photosynthetic rate $(\mathrm{Pn})$, stomatal conductance $\left(g_{\mathrm{s}}\right)$, transpiration rate $(E)$, leaf temperature $(\mathrm{Tl})$, and substomatal $\mathrm{CO}_{2}$ concentration (Ci) in response to sink-source treatments on 1-year-old shoots., ${ }^{\mathrm{z} y}$

\begin{tabular}{|c|c|c|c|c|c|c|}
\hline Cultivar & Treatment & $\operatorname{Pn}\left(\mu \mathrm{mol} \cdot \mathrm{m}^{-2} \cdot \mathrm{s}^{-1}\right)$ & $g_{\mathrm{s}}\left(\mathrm{mol} \cdot \mathrm{m}^{-2} \cdot \mathrm{s}^{-1}\right)$ & $\mathrm{E}\left(\mathrm{mmol} \cdot \mathrm{m}^{-2} \cdot \mathrm{s}^{-1}\right)$ & $\mathrm{Tl}\left({ }^{\circ} \mathrm{C}\right)$ & $\mathrm{Ci}\left(\mu \mathrm{mol} \cdot \mathrm{mol}^{-1}\right)$ \\
\hline \multirow{2}{*}{ Qingfeng } & +2 fruit & $9.90 \mathrm{a}$ & $0.191 \mathrm{a}$ & $5.46 \mathrm{a}$ & $35.3 \mathrm{~b}$ & 247.3 \\
\hline & -fruit & $4.69 \mathrm{~b}$ & $0.066 \mathrm{~b}$ & $1.80 \mathrm{~b}$ & $35.9 \mathrm{a}$ & 249.5 \\
\hline \multirow[t]{2}{*}{ Okubo } & +2 fruit & $12.39 \mathrm{a}$ & $0.396 \mathrm{a}$ & $9.02 \mathrm{a}$ & $35.8 \mathrm{~b}$ & 261.3 \\
\hline & +1 fruit & $11.39 \mathrm{~b}$ & $0.350 \mathrm{~b}$ & $8.34 \mathrm{~b}$ & $36.2 \mathrm{~b}$ & 257.3 \\
\hline \multirow[t]{4}{*}{ Yanhong } & +2 fruit & $9.02 \mathrm{a}$ & $0.191 \mathrm{a}$ & $5.10 \mathrm{a}$ & $34.8 \mathrm{~b}$ & $235.9 \mathrm{ab}$ \\
\hline & +1 fruit & $7.32 \mathrm{~b}$ & $0.144 \mathrm{~b}$ & $3.91 \mathrm{~b}$ & $34.9 \mathrm{~b}$ & $228.8 \mathrm{~b}$ \\
\hline & -fruit & $3.18 \mathrm{c}$ & $0.048 \mathrm{c}$ & $1.71 \mathrm{c}$ & $35.9 \mathrm{a}$ & $234.2 \mathrm{ab}$ \\
\hline & -fruit* & $3.07 \mathrm{c}$ & $0.049 \mathrm{c}$ & $1.80 \mathrm{c}$ & $36.0 \mathrm{a}$ & $245.2 \mathrm{a}$ \\
\hline Bayuecui & +2 fruit & $8.29 \mathrm{a}$ & $0.270 \mathrm{a}$ & $4.62 \mathrm{a}$ & $31.5 \mathrm{~b}$ & $269.2 \mathrm{a}$ \\
\hline \multirow[t]{4}{*}{ Wanmi } & +2 fruit & $9.15 \mathrm{a}$ & $0.216 \mathrm{a}$ & $4.31 \mathrm{a}$ & $29.1 \mathrm{c}$ & $281.5 \mathrm{~b}$ \\
\hline & +1 fruit & $7.21 \mathrm{~b}$ & $0.161 \mathrm{~b}$ & $3.41 \mathrm{~b}$ & $29.3 \mathrm{bc}$ & $285.6 \mathrm{~b}$ \\
\hline & -fruit & $1.69 \mathrm{c}$ & $0.042 \mathrm{c}$ & $1.05 \mathrm{c}$ & $30.3 \mathrm{a}$ & $309.0 \mathrm{a}$ \\
\hline & -fruit* & $2.27 \mathrm{c}$ & $0.054 \mathrm{c}$ & $1.29 \mathrm{c}$ & $29.9 \mathrm{ab}$ & $306.7 \mathrm{a}$ \\
\hline
\end{tabular}

${ }^{\mathrm{z}}$ Two fruit were kept inside two girdling cuts (+2 fruit); one fruit was kept inside two girdling cuts (+1 fruit); fruit were removed inside and outside two girdling cuts (-fruit); two fruit were kept outside two girdling cuts (-fruit*). Each value is the mean of all data collected on three measurement dates for each of five peach cultivars.

${ }^{\mathrm{y}}$ Within columns for each cultivar, values followed by different letters were significantly different at $P \leq 0.05$.

on the dates when $P A R$ reached above $800 \mu \mathrm{moL} \cdot \mathrm{m}^{-2} \cdot \mathrm{s}^{-1}$, Pn quickly increased in the morning and remained high until 1500 or $1600 \mathrm{HR}$, or else it was relatively low throughout the day. Usually, higher Pn values were observed for +2 fruit than for +1 fruit when $P A R$ was above $\approx 800 \mu \mathrm{mol} \cdot \mathrm{m}^{-2} \cdot \mathrm{s}^{-1}$ (Fig. $2 \mathrm{~A}$ and $\mathrm{C}$ ), while the difference between the +2 fruit and +1 fruit treatments became much smaller or even disappeared when $P A R$ was below about $800 \mu \mathrm{mol} \cdot \mathrm{m}^{-2} \cdot \mathrm{s}^{-1}$ (Fig. 2B). Pn for -fruit and -fruit* treatments were much lower than those for +2 fruit and +1 fruit treatments, except for some early morning and late afternoon when $P A R$ was very low. There was no obvious difference in $P n$ between -fruit and -fruit* irrespective of $P A R$.

Similarly, $g_{\mathrm{s}}$ (Fig. 2D-F) and E (Fig. 2G-I) were influenced by sink-source treatments and exhibited similar diurnal variations with $\mathrm{Pn}$ on all measurement dates. Usually from 1000 to $1500 \mathrm{HR}$, Tl values of -fruit and -fruit* treatments were significantly higher than for +2 fruit and +1 fruit treatments (Fig. 2J and L), except for 'Wanmi' when $P A R$ was below $800 \mu \mathrm{mol} \cdot \mathrm{m}^{-2} \cdot \mathrm{s}^{-1}$ throughout the day (Fig. $2 \mathrm{~K}$ ). Moreover, leaf temperature was similar for - fruit and - fruit* and for +2 fruit and +1 fruit treatments, respectively.

Ci for the +1 fruit treatment was similar to those for the +2 fruit treatment. They generally decreased during the morning and then tended to increase in the late afternoon (Fig. 2M-O). Diurnal variations of $\mathrm{Ci}$ in -fruit and -fruit* treatments depended on measurement date. When $P A R$ was above $\approx 800$ $\mu \mathrm{mol} \cdot \mathrm{m}^{-2} \cdot \mathrm{s}^{-1}, \mathrm{Ci}$ in -fruit and -fruit* treatments were generally higher than those in +1 fruit and +2 fruit treatments (Fig. $2 \mathrm{M}$ and O). For 'Yanhong', however, Ci did not differ among sinksource treatments even when $P A R$ exceeded $\approx 800 \mu \mathrm{mol} \cdot \mathrm{m}^{-2} \cdot \mathrm{s}^{-1}$ on the third day after removing fruit (data not shown). When $P A R$ was below $\approx 800 \mu \mathrm{mol} \cdot \mathrm{m}^{-2} \cdot \mathrm{s}^{-1}$ throughout the day (Fig.
$2 \mathrm{~N}$ ), Ci for -fruit and -fruit* treatments were generally lower than or similar to those for +1 fruit and +2 fruit treatments.

Relationships among photosynthetic PaRAMETERS. The relationship between Pn and $g_{\mathrm{s}}$ was shown in Fig. 3. A logarithmic curve described the relationship between $g_{\mathrm{s}}$ and Pn for the five cultivars $(r=0.81$ to $0.94, P \leq 0.001)$. Pn generally increased rapidly at lower rates of $g_{\mathrm{s}}$ and then increased more slowly at high rates of $g_{\mathrm{s}}$. The relationship between Pn and Tl across all treatments was similar for each cultivar (Fig. 4). Pn seemed to increase with $\mathrm{Tl}$ until $\mathrm{Tl}$ reached a critical level. Above the critical temperature, Pn generally tended to decrease. The critical leaf temperature could be roughly indicated as $37^{\circ} \mathrm{C}$ for 'Qingfeng', $39^{\circ} \mathrm{C}$ 'Okubo', $38^{\circ} \mathrm{C}$ for 'Yanhong', $35^{\circ} \mathrm{C}$ for 'Bayuecui', and $34^{\circ} \mathrm{C}$ for 'Wanmi'. The relationship between $\mathrm{Ci}$ and PAR was also analyzed (Fig. 5). Ci values of -fruit and -fruit* treatments were generally higher than those of + fruit and +2 fruit treatments for 'Wanmi' (Fig. 5E). With respect to the other four cultivars (Fig. 5A-D), Ci of -fruit and -fruit* treatments were generally lower than those of + fruit and +2 fruit treatments when $P A R$ was below $\approx 800 \mu \mathrm{mol} \cdot \mathrm{m}^{-2} \cdot \mathrm{s}^{-1}$ for 'Yanhong' and 'Bayuecui' and below $\approx 1200 \mu \mathrm{mol} \cdot \mathrm{m}^{-2} \cdot \mathrm{s}^{-1}$ for 'Qingfeng' and 'Okubo'. When $P A R$ was above these levels, Ci values were higher or lower than those in +1 fruit and +2 fruit treatments.

\section{Discussion}

Most plant tissues act as water reservoirs, and the redistribution of water can be modified by both water potential gradients and the various resistances to water transport within the plant (Huguet, 1985). Water stored in phloem can be released into the transpiration stream under high irradiance. Girdling blocks not 


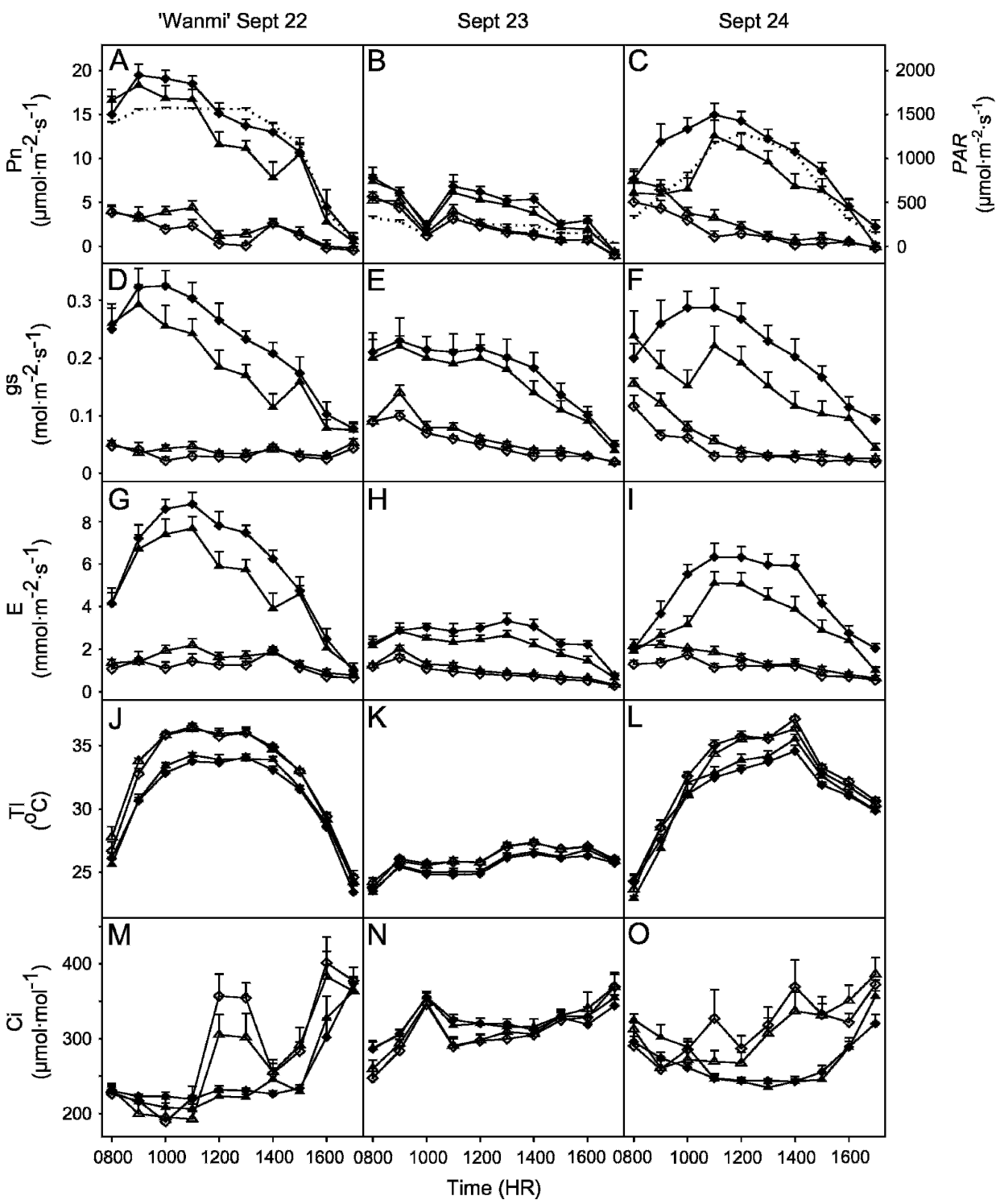

Fig. 2. Diurnal variations in photosynthetically active radiation (PAR, - - -), net photosynthetic rate (Pn), stomatal conductance $\left(g_{\mathrm{s}}\right)$, transpiration rate $(\mathrm{E})$, leaf temperature $(\mathrm{Tl})$, and substomatal $\mathrm{CO}_{2}$ concentration (Ci) in response to sink-source treatments on 1-year-old shoots [+2 fruit (solid tilted squares), two fruit were kept inside two girdling cuts; +1 fruit $(\boldsymbol{\Delta})$, one fruit was kept inside two girdling cuts; -fruit (open tilted squares), fruit were removed inside and outside two girdling cuts; -fruit* $(\triangle)$, two fruit were kept outside two girdling cuts] for 'Wanmi' peach. Each value is the mean with + SE $(n=7-10)$.

only assimilate transport but also the movement of stored water from the phloem. In this study, the effect of water transport from the phloem could be negligible because the phloem was physically interrupted for all treatments. On the other hand, fruit may be an important temporary water reservoir (Huguet et al., 1992). Outflow of water from fruit during the day, as shown by fruit shrinkage, may influence the water status of adjacent leaves. Removing or retaining fruit has often been used in studies of source-sink relationships (Syvertsen et al., 2003). To detect the influence of water in retained fruit on leaf photosynthesis, we set up two comparable treatments: removing the fruit both inside and outside two girdling cuts (-fruit) and keeping two fruit only outside two girdling cuts (-fruit*) on 1-year-old shoots. Under this condition, assimilate transport was blocked between the treated and nonexperimental parts for both -fruit and -fruit* treatments, but water in retained fruit could flow into the leaves on 1-yearold shoot via xylem in the -fruit* treatment. There was no significant difference in mean or diurnal Pn, as well as $g_{\mathrm{s}}$ and E, of the source leaves between -fruit and -fruit* treatments (Table 1; Fig. 2). The water outflow from fruit into leaves was too small to influence stomatal closure in wellirrigated trees. Therefore, compared with fruit removal (-fruit), the higher net photosynthesis in +1 fruit and +2 fruit treatments would not be due to water status of source leaves as influenced by the retained fruit.

Five peach cultivars with different maturity dates were used in this study to investigate genotypic factor. Consistent results were obtained with the five cultivars: Pn tended to increase with increased sink demand, accompanied with an increase in $g_{\mathrm{s}}$ and $\mathrm{E}$ and a decrease of $\mathrm{Tl}$. The common results suggested that the response of leaf photosynthesis to sink-source manipulation could be independent of genetic background in peach. It was reported that no significant difference in leaf gas-exchange characteristics was observed between fruiting and defruited peach trees during the early stages of fruit growth (DeJong, 1986). This study used entire trees to manipulate source-sink relationships. In the entire tree, other organs besides fruit, such as roots, stems, and new shoots, are also important sinks. Sink demand of fruit may differ among phenological stages and may vary among trees. Perhaps the adjustment of photosynthesis may appear only after a specific reduction in sink demand, or a threshold response to decreased sink demand may exist. For example, on adult plants of cucumber (Cucumis sativus L.) and tomato, reduction of Pn was observed only when all fruit and flowers were removed (Gucci and Flore, 1989; Marcelis, 1991). Therefore, a 1-year-old shoot could be more responsive to modified sink demand by removing versus retaining fruit and may be better than an entire tree for the study of photosynthetic responses to sink-source relationship.

A significant relationship between $\mathrm{Pn}$ and $g_{\mathrm{s}}$ over a range of $g_{\text {s }}$ values was observed in the present study as has been shown previously (Gutschick and Simonneau, 2002; Tan and Buttery, 1986). Li et al. (2005, 2007) and Duan et al. (2007) showed that decreased Pn under low sink demand was mainly due to a nonstomatal limitation. In this study, higher and lower $\mathrm{Ci}$ occurred in -fruit and -fruit* treatments than in +fruit and +2 fruit treatments, indicating that decreased Pn could be due to both nonstomatal and stomatal limitations. Further analysis of the relationship between $\mathrm{Ci}$ and $P A R$ showed that the difference in 


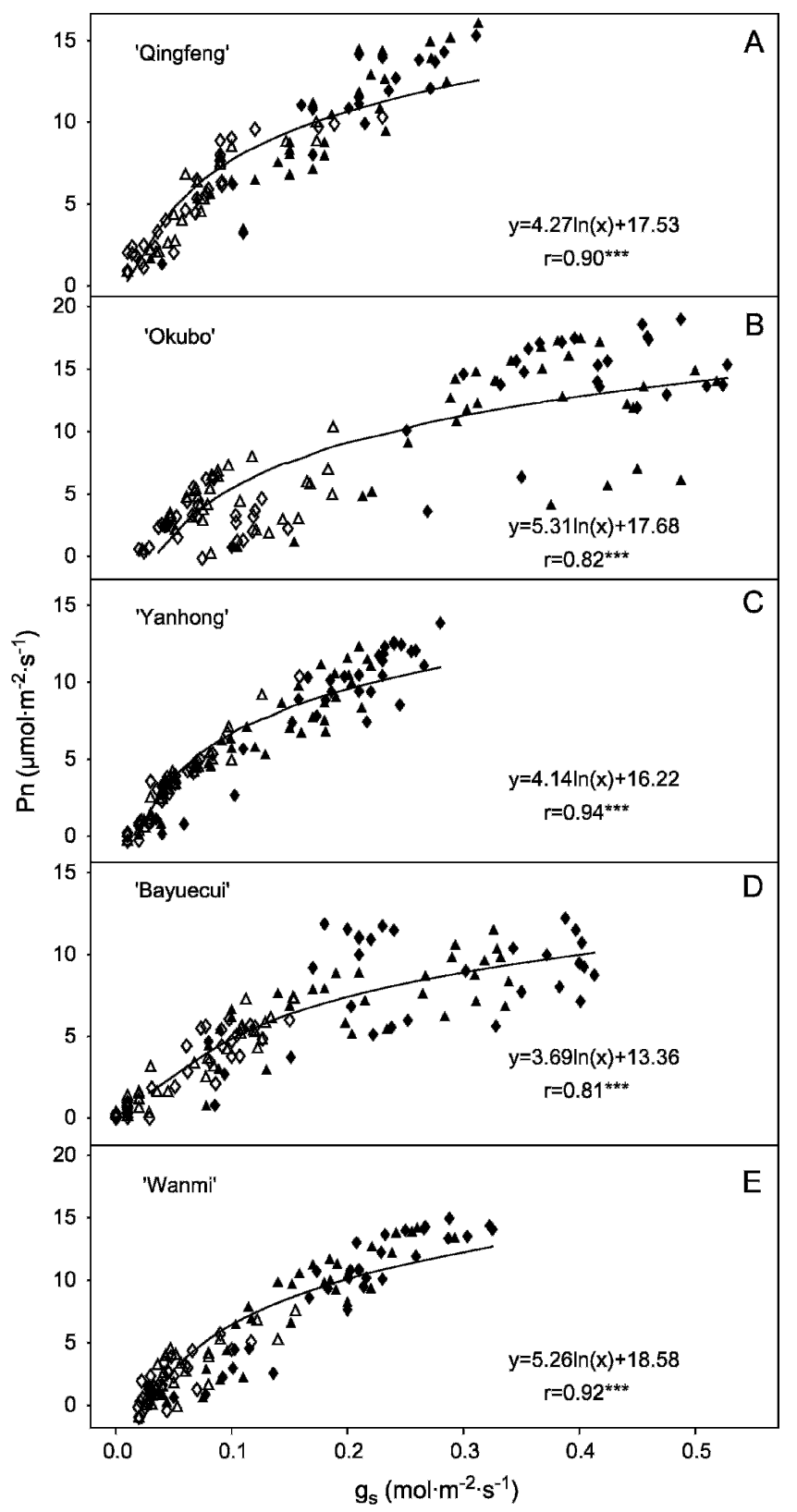

Fig. 3. Relationship between net photosynthetic rate (Pn) and stomatal conductance $\left(g_{\mathrm{s}}\right)$ among sink-source treatments on 1-year-old shoots $[+2$ fruit (solid tilted squares), two fruit were kept inside two girdling cuts; +1 fruit ( $\boldsymbol{\Delta}$ ), one fruit was kept inside two girdling cuts; -fruit (open tilted squares), fruit were removed inside and outside two girdling cuts; - fruit* $(\triangle)$, two fruit were kept outside two girdling cuts] for peach cultivars Qingfeng, Okubo, Yanhong, Bayuecui, and Wanmi. Data are mean values from three measurement dates for each cultivar.

Ci between fruit removal and retention depended on $P A R$. When $P A R$ was above $800 \mu \mathrm{mol} \cdot \mathrm{m}^{-2} \cdot \mathrm{s}^{-1}$ for 'Yanhong' and 'Bayuecui' and above $1200 \mu \mathrm{mol} \cdot \mathrm{m}^{-2} \cdot \mathrm{s}^{-1}$ for 'Qingfeng' and 'Okubo', $\mathrm{Ci}$ in fruit-removal treatments were either higher or lower than those with fruit. However, under these $P A R$ levels, a lower $\mathrm{Ci}$ in fruitremoval treatments was always found. Under a high level of $P A R$, a reduced $\mathrm{E}$ due to stomatal closure sharply increased $\mathrm{Tl}$. A high $\mathrm{Tl}$ above a critical level subsequently could have weakened the activities of enzymes related to assimilate metabolism caused irreversible damage to chloroplast structures or changed bio-

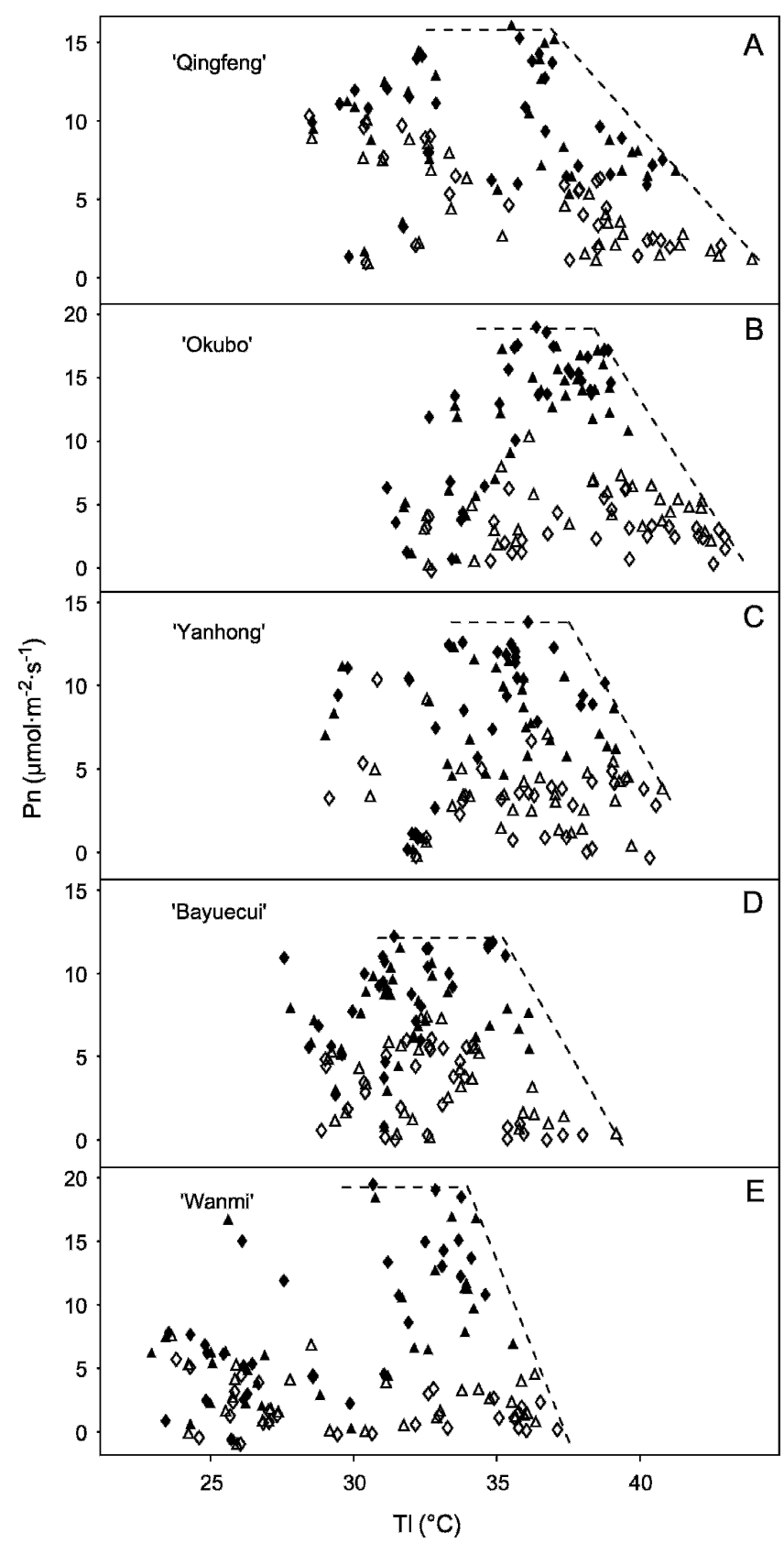

Fig. 4. Relationship between net photosynthetic rate $(\mathrm{Pn})$ and leaf temperature (Tl) among sink-source treatments on 1-year-old shoots [ +2 fruit (solid tilted squares), two fruit were kept inside two girdling cuts; +1 fruit $(\boldsymbol{\Lambda})$, one fruit was kept inside two girdling cuts; -fruit (open tilted squares), fruit were removed inside and outside two girdling cuts; - fruit* $(\triangle)$, two fruit were kept outside two girdling cuts] for peach cultivars Qingfeng, Okubo, Yanhong, Bayuecui, and Wanmi. Data were mean values from three measurement dates for each cultivar.

chemical properties and functionality of the thylakoid membrane (Berry and Björkman, 1980; Pastenes and Horton, 1996). The excessive energy with high PAR under low sink demand also could lead to the damage of PSII reaction-centers and decrease electron transport efficiency and photochemical efficiency (Duan et al., 2007; Li et al., 2007). These effects may explain why nonstomatal limitation under low sink demand took place primarily under high $P A R$. 


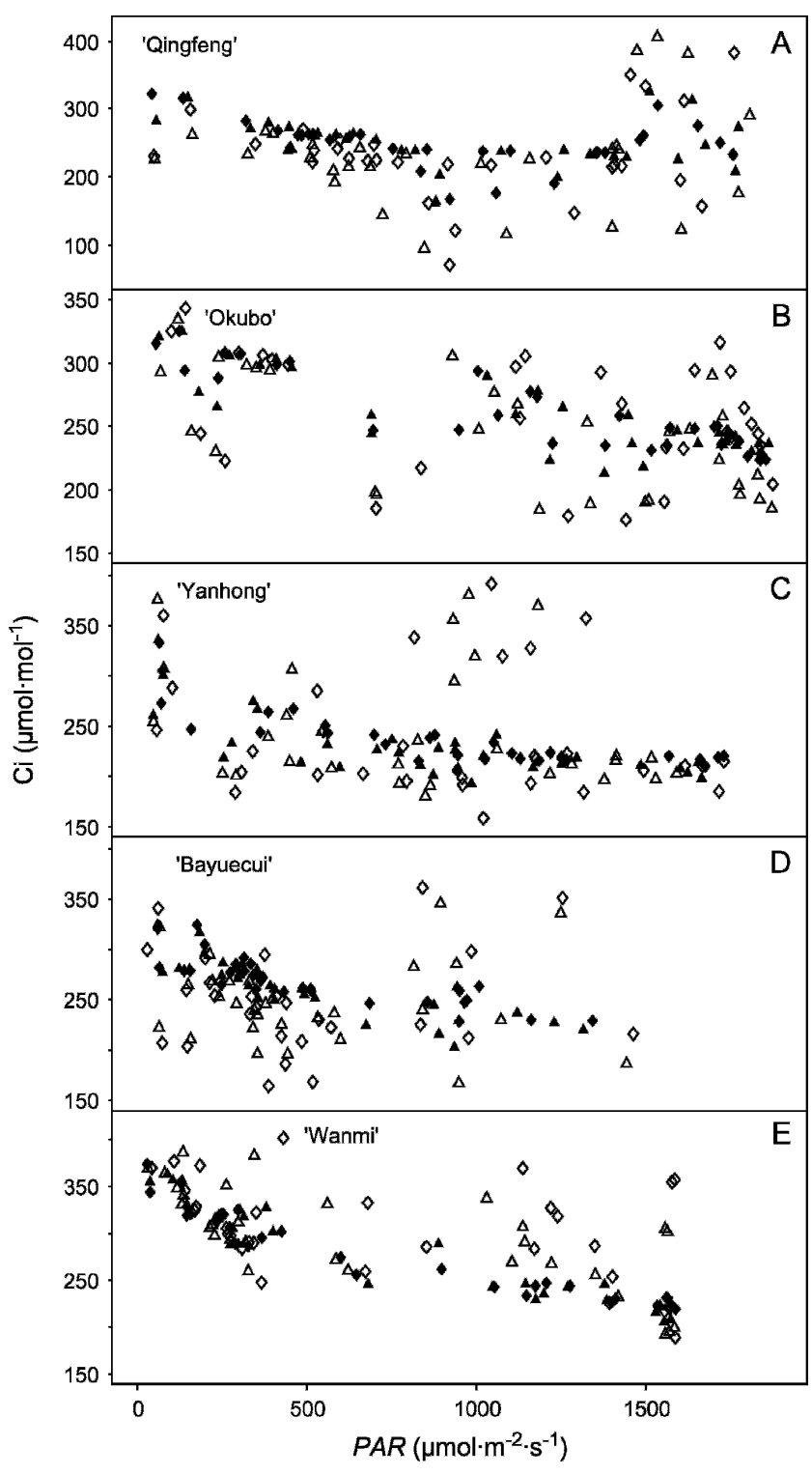

Fig. 5. Relationship between substomatal $\mathrm{CO}_{2}$ concentration $(\mathrm{Ci})$ and photosynthetically active radiation $(P A R)$ among sink-source treatments on 1-yearold shoots $[+2$ fruit (solid tilted squares), two fruit were kept inside two girdling cuts; +1 fruit $(\boldsymbol{\Lambda})$, one fruit was kept inside two girdling cuts; - fruit (open tilted squares), fruit were removed inside and outside two girdling cuts; -fruit* $(\triangle)$, two fruit were kept outside two girdling cuts] for peach cultivars Qingfeng, Okubo, Yanhong, Bayuecui, and Wanmi. Data were mean values from three measurement dates for each cultivar.

\section{Literature Cited}

Berry, J. and O. Björkman. 1980. Photosynthetic response and adaptation to temperature in higher plants. Annu. Rev. Plant Physiol. 31:491-543.

Buwalda, J.G. and G.S. Smith. 1990. Effect of partial defoliation at various stages of the growing season on fruit yields, root growth, and return bloom of kiwifruit vines. Scientia Hort. 42:29-44.

DeJong, T.M. 1986. Fruit effects on photosynthesis in Prunus persica. Physiol. Plant. 66:149-153.

Downton, W.J.S., W.J.R. Grant, and B.R. Loveys. 1987. Diurnal changes in the photosynthesis of field-grown grape vines. New Phytol. 105:71-80.
Duan, W., P.G. Fan, L.J. Wang, W.D. Li, S.T. Yan, and S.H. Li. 2008. Photosynthetic response to low sink demand after fruit removal in relation to photoinhibition and photoprotection in peach trees. Tree Physiol. 28:123-132.

Gucci, R. and J.A. Flore. 1989. The effect of fruiting or fruit removal on leaf photosynthesis and dry matter distribution of tomato. Adv. Hort. Sci. 3:120-125.

Gutschick, V.P. and T. Simonneau. 2002. Modelling stomatal conductance of field-grown sunflower under varying soil water content and leaf environment: Comparison of three models of stomatal response to leaf environment and coupling with an abscisic acidbased model of stomatal response to soil drying. Plant Cell Environ. 25:1423-1434.

Huguet, J.G., S.H. Li, J.Y. Lorendeau, and G. Pelloux. 1992. Specific micromorphometric reaction of fruit trees to water stress and irrigation scheduling automation. J. Hort. Sci. 67:631-640.

Huguet, J.G. 1985. Appréciation de l'état hydrique d'une plante à partir des variations micrométriques de la dimension des fruits ou des tiges au cous de la journée. Agronomie 5:733-741.

Iglesias, D.J., I. Lliso, F.R. Tadeo, and M. Talon. 2002. Regulation of photosynthesis through source:sink imbalance in citrus is mediated by carbohydrate content in leaves. Physiol. Plant. 116:563-572.

Li, S.H., M. Genard, C. Bussi, J.G. Huguet, B. Habib, J. Besset, and R. Laurent. 2001. Fruit quality and leaf photosynthesis in response to microenvironment modification around individual fruit by covering the fruit with plastic in nectarine and peach trees. J. Hort. Sci. Biotechnol. 76:61-69.

Li, W.D., S.H. Li, S.H. Yang, J.M. Yang, X.B. Zheng, X.D. Li, and H.M. Yao. 2005. Photosynthesis in responses to sink-source manipulations during different phenological stages of fruit development in peach trees: Regulation by stomatal aperture and leaf temperature. J. Hort. Sci. Biotechnol. 80:481-487.

Li, W.D., D. Wei, P.G. Fan, S.T. Yan, and S.H. Li. 2007. Photosynthesis in response to sink-source activity in relation to end products and activities of metabolic enzymes in peach trees. Tree Physiol. 27:1307-1318.

Marcelis, L.F.M. 1991. Effect of sink demand on photosynthesis in cucumber. J. Expt. Bot. 42:1387-1392.

Okuda, H., T. Kihara, and I. Iwagaki. 1996. Effects of fruit removal on photosynthesis, stomatal conductance and ABA level in the leaves of vegetative shoots in relation to flowering of Satsuma mandarin. J. Jpn. Soc. Sci. 65:15-20.

Pastenes, C. and P. Horton. 1996. Effect of high temperature on photosynthesis in beans. Plant Physiol. 112:1245-1251.

Pavel, E.W. and T.M. DeJong. 1993. Source and sink-limited growth periods of developing peach fruit indicated by relative growth rate analysis. J. Amer. Soc. Hort. Sci. 132:44-51.

Quilot, B., M. Génard, and J. Kervella. 2004. Leaf light-saturated photosynthesis for wild and cultivated peach genotypes and their hybrids: A simple mathematical modelling analysis. J. Hort. Sci. Biotechnol. 79:546-553.

Roper, T.R., J.D. Keller, W.H. Loescher, and C.R. Rom. 1988. Photosynthesis and carbohydrate partitioning in sweet cherry: Fruiting effects. Physiol. Plant. 72:42-47.

Syvertsen, J.P., C. Goñi, and A. Otero. 2003. Fruit load and canopy shading affect leaf characteristics and net gas exchange of 'Spring' navel orange trees. Tree Physiol. 23:899-906.

Tan, C.S. and B.R. Buttery. 1986. Photosynthesis, stomatal conductance, and leaf water potential in response to temperature and light in peach. HortScience 21:1180-1182.

Walker, A.J. and L.C. Ho. 1977. Carbon translocation in the tomato, carbon import and fruit growth. Ann. Bot. (Lond.) 41:813-823.

Zhang, S., Q. Li, K. Ma, and L. Chen. 2001. Temperature-dependent gas exchanges and stomatal/non-stomatal limitation to $\mathrm{CO}_{2}$ assimilation of Quercus liaotungensis under midday high irradiance. Photosynthetica 39:383-388. 